\title{
Evaluation of Increase Weight in a Wing Fixed Leading Edge Design to Support UAS Impact
}

\author{
Tomaz Drumond, Marcelo Greco and Carlos Cimini \\ Department of Structural Engineering, Federal University of Minas Gerais, Belo Horizonte, Minas Gerais/Brazil \\ E-mail: tomdrud@ufmg.br,mgreco@dees.ufmg.br,cimini@ufmg.br
}

\begin{abstract}
In recent years, the number of Unmanned Aerial Systems (UAS) operating in the sky of urban centres has quite increased due to the facilities to purchase this type of vehicle. Consequently, the risk of an airborne impact between these vehicles and manned aircrafts has been target of concern with incidents been reported recently. Although the current aircrafts had been designed to support bird strikes, a collision with an UAS could be more critical, as reported in a study published by the Federal Aviation Administration (FAA) in 2016. In the present paper, a commercial aircraft Wing Fixed Leading Edge (WFLE) was first designed to support a bird strike. Then, its skin and spar thicknesses were increased so the WFLE could withstand an impact with an UAS. The safety criterion adopted was that the lithium-ion battery from the UAS could not penetrate into the airframe when the impact occurs at the airliner cruising speed. Finally, the weight from both WFLE configurations were compared so the mass increase could be quantified. During simulation, the same mass was considered for the UAS and the bird, although they were modelled using different materials. Modelling procedures were verified with test data found in other papers and the results obtained presented acceptable correlation. The UAS considered was a quadcopter configuration intended for recreational and commercial aerial photography with a $1.8 \mathrm{~kg}$ mass. The results showed that spar thicknesses increase were more effective than increases in the skin thicknesses.
\end{abstract}

Keywords: UAS Impact, Bird Strike, Wing Fixed Leading Edge, Simulation

\section{Introduction}

The amount of Unmanned Aerial Systems (UAS) being operated all over the world on recent years has increased significantly. The Association for Unmanned Vehicles Systems International (AUCSI) estimates that in 2020 the number of UAS sold around the world could reach 4.7 million unities [1]. The Federal Aviation Administration (FAA) forecasts that in the United States, the sale of commercial UAS for private purposes will go from US\$2.5 million in 2016 to US\$7.0 million in 2020 [2]. Associated with these increase in the number of UAS being operated in airspaces, it raises the necessity to regulate how these vehicles are used. In Brazil for example, it was created the Brazilian Civil Aviation Special Regulation $\mathrm{n}^{\circ}$ 94/2019 (RBAC-E $\mathrm{n}^{\circ}$ 94/2017) by the National Civil Aviation Agency (ANAC); the ICA 100-400 - Remotely Piloted Aircraft Systems and Access to the Brazilian Airspace, by the Department of Airspace Control (DECEA), and the Drones Homologation Booklet, established by the National Telecommunications Agency (ANATEL).
Among the concerns raised by the growing number of UAS is the risk of mid-air impact occurring between this type of vehicle and an aircraft that is flying. In order to avoid such kind of occurrence, helicopters for rescuing and fighting fires have already been impeded to fly when UAS were seeing being operated near the take-off region. In addition, airports have been temporarily closed when UAS were identified operating in their proximities, causing discomfort for a large number of passengers and significant financial losses to airlines companies.

In addition to the troubles caused on airports, mid-air impacts between UAS and aircrafts has possibly occurred in the United Kingdom [3], Canada and, more recently, in Mexico.

Sharma [2] has performed an investigation into UAS incidents considering reports released by the FAA and the NASA. The results have shown an increase in the number of occurrences, as indicated in tab.1. 
Table 1: FAA Aviation Safety Reporting System - Number of UAS-related Events (1993-June 1, 2016) (adapted from Sharma [2])

\begin{tabular}{|c|c|c|c|}
\hline Year & $\begin{array}{c}\text { Number } \\
\text { of Events }\end{array}$ & Year & $\begin{array}{c}\text { Number } \\
\text { of Events }\end{array}$ \\
\hline 1993 & 5 & 2005 & 1 \\
\hline 1994 & 4 & 2006 & 6 \\
\hline 1995 & 7 & 2007 & 8 \\
\hline 1996 & 3 & 2008 & 7 \\
\hline 1997 & 5 & 2009 & 4 \\
\hline 1998 & 10 & 2010 & 10 \\
\hline 1999 & 3 & 2011 & 9 \\
\hline 2000 & 10 & 2012 & 24 \\
\hline 2001 & 5 & 2013 & 32 \\
\hline 2002 & 1 & 2014 & 87 \\
\hline 2003 & 3 & 2015 & 190 \\
\hline 2004 & 2 & 2016 & 88 \\
\hline
\end{tabular}

Although the incidents reported so far have not resulted in death of any of the crewmembers or passengers on board, the risk involved in such an event is extremely high. Aircrafts operating in the world today are not designed to withstand an UAS impact since there are no requirements for manufacturers to prove their aircraft's ability to land in secure after being hit by a stiffener component like an UAS.

Meng et al. [4] and Olivares et al. [5] has showed that an midair impact with UAS of equivalent mass causes more severe damage to an aircraft than a bird impact on empennages, wing, windshield and engine. This seems to be due to the fact that UAS components are more rigid than the organs of a bird. Studies such as the performed by the British Military Aviation Authority [6] have been carried out to better understand the phenomena and the criticality that UAS impact can lead to an aircraft.

In the future, new aircraft structures should be reinforced to withstand this kind of impact, resulting in an increase in aircraft and helicopters weights.

The objective of the present work is to quantify the mass increase in an aircraft wing fixed leading edge after being reinforced to withstand a $1.8 \mathrm{~kg}$ UAS impact, similar to the mass of a bird established on requirement FAR 25.571 (e).

Firstly, the Wing Fixed Leading Edge (WFLE) of a commercial aircraft is designed to withstand an impact with a $1.8 \mathrm{~kg}$ bird. The WFLE skin thickness is increased in a way that no rupture could be verified in the structure after being impact by the bird. Further, an impact simulation with an UAS quadcopter of similar mass is performed. Since the UAS impact induces larger damages in the aircraft than the bird, the WFLE skin and spar thickness will be increased one more time in order to increase the wing strength. Finally, the weight of the WFLE capable to withstand the UAS impact is compared with the configuration able to resist the bird strike.

\section{Description of the FE model}

\subsection{Wing Fixed Leading Edge (WFLE)}

The wing fixed leading edge of a commercial aircraft was modelled considering its FLE Ribs, Main Box Ribs, Skin and Spar as shown in fig. 1. Only shell elements were used and the WFLE components were connected using coincident nodes. Fixed constraints were set on the Skin, Main Box Ribs and Spar edges since only a segment of the aircraft was represented in order to reduce computational costs.

The materials considered on WFLE structures were the Aluminium 2024-T3 for the Skin and the Aluminium 7050T7451 for both types of Ribs and Spar.

Gokhale et al. [7] and Olivares et al. [8] established a quality mesh criteria that were adopted for modelling the aircraft structures on the present work. Table 2 summarizes these quality mesh criteria.

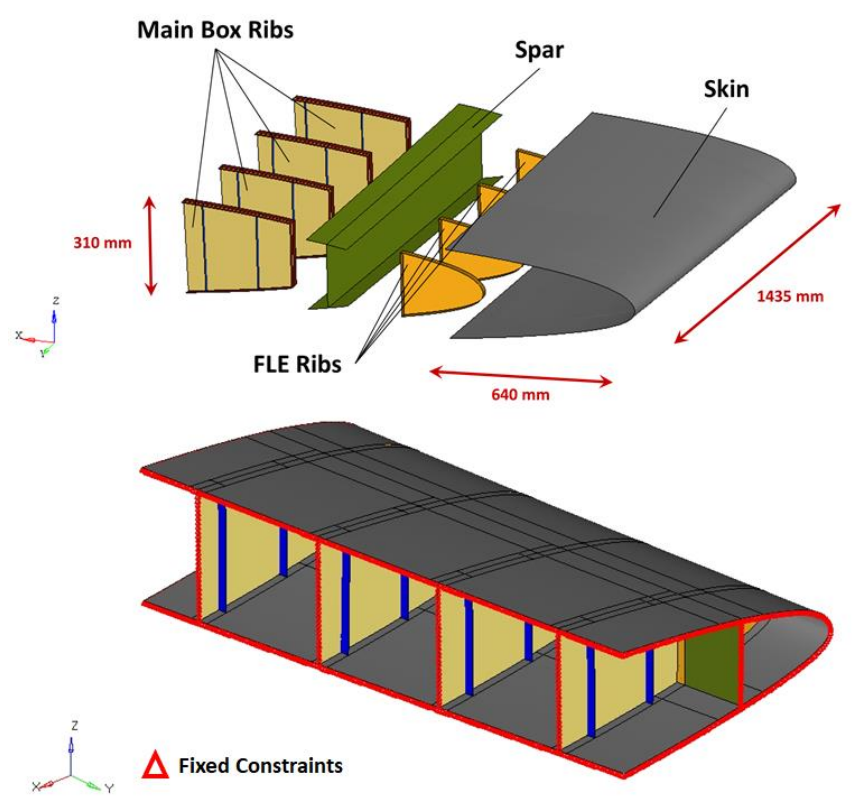

Figure 1: Wing Fixed Leading Edge FEM

Table 2: Criteria for Mesh Quality

\begin{tabular}{|c|c|c|}
\hline & Minimum & Maximum \\
\hline Warp Angle & - & $10^{\circ}$ \\
\hline Aspect Ratio & - & 5 \\
\hline Skew & - & $45^{\circ}$ \\
\hline Jacobian & 0,6 & - \\
\hline Distortion & 0,6 & - \\
\hline Stretch & 0,2 & - \\
\hline QUAD angles & $45^{\circ}$ & $135^{\circ}$ \\
\hline TRIA angles & $20^{\circ}$ & $120^{\circ}$ \\
\hline Taper & - & 0,5 \\
\hline Element Size & $5 \mathrm{~mm}$ & $8 \mathrm{~mm}$ \\
\hline \multicolumn{2}{|r}{}
\end{tabular}




\subsection{The UAS Quadcopter}

The UAS quadcopter model selected to be used on impact analysis on the WFLE was the DJI Phantom 3 Standard. Cairns et. al [9] reported that the DJI Phantom UAS family had been the most common model found in the market and for this reason, the DJI Phantom was selected. The referred UAS weights approximately $1.2 \mathrm{~kg}$ and its dimensions are about $290 \mathrm{~mm}$ x $290 \mathrm{~mm} \times 185 \mathrm{~mm}$.

To represent the UAS in a FE model only its most stiffener structures (battery, engines and camera) were detailed in the model. Solid elements were used to represent such components, which were connected by means of bar elements. The UAS model is shown on fig. 2 and its components materials were considered as follows:

- Battery cells constructed using lithium-ion polymer (LiPo) technology;

- Motors with an Aluminium Alloy A520.0-F rotor and a laminated steel AISI 4130 core stator;

- Camera made of Aluminium Alloy A520.0-F;

- UAS body and gimbal made of polycarbonate material, as reported in Olivares et al. [8]. The polycarbonate was attributed to bar elements that connect the other UAS components.

Although the UAS components have their own internal structures, they were considered as homogenous entities to simplify the simulation model. The bar elements had their material density adjusted in order to make the weight of UAS FE model be the same from a real UAS $(\sim 1.2 \mathrm{~kg})$

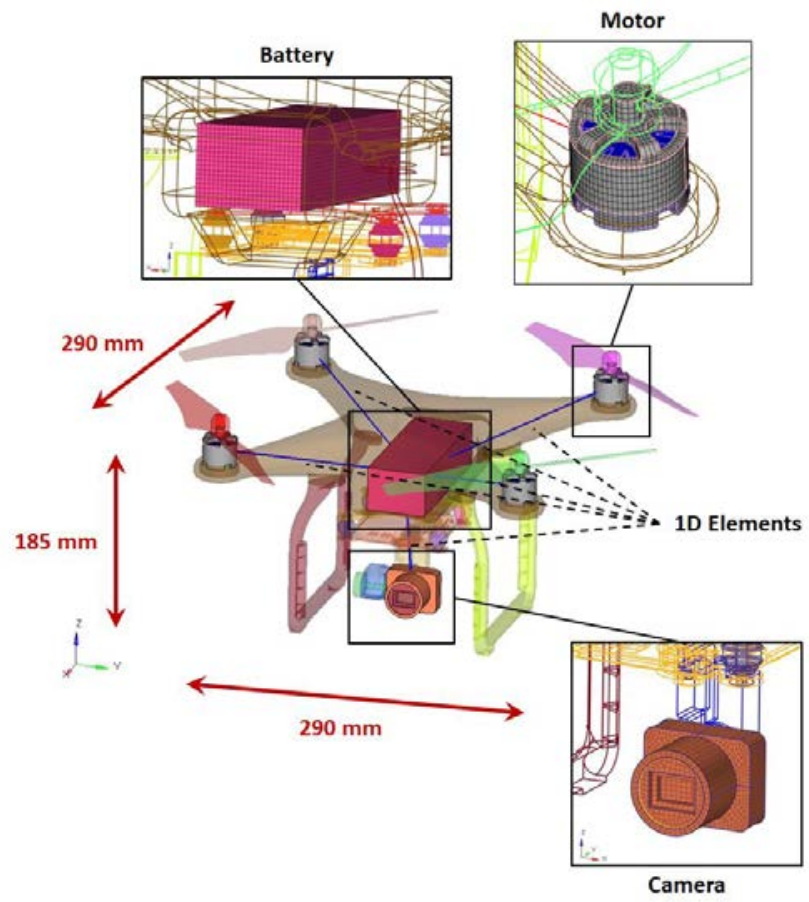

Figure 2: FE mesh for different UAS components

Further, with the UAS model completed, all its material densities were increased by a 1.5 factor $(1.8 \mathrm{~kg} / 1.2 \mathrm{~kg}=1.5)$ in order to make the UAS model mass equivalent to the bird requirement from FAR 25.571(e).

\subsection{Constitutive Model for Materials}

The Aluminium alloy 2024-T3 on WFLE Skin was modelled as an elastic-plastic material with isotropic damage model, flow stress and strain rate dependent behaviour described by Johnson-Cook's law [10] defined as:

$$
\sigma=\left[A+B\left(\bar{\varepsilon}^{p}\right)^{n}\right]\left[1+C \ln \left(\dot{\varepsilon}^{*}\right)\right]\left[1-\left(T^{*}\right)^{m}\right]
$$

Where $\sigma$ is the effective stress, $\varepsilon^{p}$ the equivalent plastic strain, $\dot{\varepsilon}^{*}$ the dimensionless plastic strain rate and $\mathrm{T}^{*}$ the temperature rising during plastic deformation. Temperature influence was not consider during the analysis performed here, so only first and second terms of eq. (1) were taken in account. $A, B, C, m$ and $n$ are parameters obtained through static tests, which values for Al 2024-T3 were obtained on Kay [11] and are summarized in tab. 3 .

Table 3: Johnson-Cook Parameters for Al 2024-T3 [11]

\begin{tabular}{|c|c|c|c|c|c|}
\hline & $\begin{array}{c}\mathrm{A} \\
{[\mathrm{MPa}]}\end{array}$ & $\begin{array}{c}\mathrm{B} \\
{[\mathrm{MPa}]}\end{array}$ & $\mathrm{C}$ & $\mathrm{m}$ & $\mathrm{n}$ \\
\hline \multirow{4}{*}{$\mathrm{Al} 2024-\mathrm{T} 3$} & 369.0 & 684.0 & 0.0083 & 1.7 & 0.73 \\
\cline { 2 - 6 } & $\mathrm{D}_{1}$ & $\mathrm{D}_{2}$ & $\mathrm{D}_{3}$ & $\mathrm{D}_{4}$ & $\mathrm{D}_{5}$ \\
\cline { 2 - 6 } & 0.112 & 0.123 & 1.500 & 0.007 & 0.0 \\
\hline
\end{tabular}

During the collision process, most of the skin material failure was due to tensile stretching caused by the displacement of the impact region. The strain at fracture is defined by eq. (2) and the mesh elimination criterion is activated when damage parameter D defined on eq. (3) exceeds 1.0.

$$
\varepsilon_{\text {failure }}=\left[D_{1}+D_{2} \exp \left(D_{3} \sigma^{*}\right)\left|1+D_{4} \ln \left(\dot{\varepsilon}^{*}\right)\right| 1+D_{5} T^{*}\right]
$$

Where $\sigma^{*}$ is the ratio of the pressure to the effective stress and $D_{i}$ are parameters obtained through static tests.

$$
D=\sum \frac{\Delta \bar{\varepsilon}^{p}}{\varepsilon_{\text {failure }}}
$$

Where $\Delta \varepsilon^{p}$ is the accumulated incremental effective plastic strain.

The Aluminium 7050-T7451 applied on the WFLE Ribs and Spar, the Aluminium Casting Alloy A520.0-F and the Steel Alloy AISI4130 on UAS camera and motors were represented with a bi-linear elastic plastic material with criterion for element elimination being the maximum tensile strain value. Bi-linear elastic-plastic materials parameters are shown on tab. 4. 
Table 4: Bi-linear Elastic Plastic Parameters

\begin{tabular}{|c|c|c|c|c|c|c|}
\hline & $\begin{array}{c}\rho \\
{\left[\mathrm{kg} / \mathrm{m}^{3}\right]}\end{array}$ & $\begin{array}{c}\mathrm{E} \\
{[\mathrm{GPa}]}\end{array}$ & $v$ & $\begin{array}{c}\sigma_{\mathrm{y}} \\
{[\mathrm{MPa}]}\end{array}$ & $\begin{array}{c}\mathrm{E}_{\mathrm{t}} \\
{[\mathrm{MPa}]}\end{array}$ & $\varepsilon_{\max }$ \\
\hline $\begin{array}{c}\mathrm{Al} 7050- \\
\mathrm{T} 7451 \\
{[12]}\end{array}$ & 2770. & 71. & 0.33 & 462. & 663. & 0.10 \\
\hline $\begin{array}{c}\mathrm{A} 520.0-\mathrm{F} \\
{[13]}\end{array}$ & 2600. & 66. & 0.33 & 170. & 1164. & 0.14 \\
\hline $\begin{array}{c}\mathrm{AISI} 4130 \\
{[12]}\end{array}$ & 7850. & 200. & 0.32 & 483. & 1174. & 0.12 \\
\hline
\end{tabular}

Based on the study published by Sahraei et al. [14], the UAS pounch lithium-ion batteries were considered as a crushable foam with a $60 \%$ porosity of the active particles and voids filled with electrolyte. The basic parameters obtained on Sahraei et al. [14] are listed in tab. 5.

Table 5: Mechanical Properties of the Battery [14]

\begin{tabular}{|c|c|c|c|c|}
\hline $\begin{array}{c}\text { Compressive } \\
\text { Stress }[\mathrm{MPa}]\end{array}$ & $\begin{array}{c}\rho \\
{\left[\mathrm{kg} / \mathrm{m}^{3}\right]}\end{array}$ & $\begin{array}{c}\mathrm{E} \\
{[\mathrm{GPa}]}\end{array}$ & $v$ & $\varepsilon_{\max }$ \\
\hline$\sigma=276 . \varepsilon^{1.8}$ & 1750 & 500 & 0.01 & 0.16 \\
\hline
\end{tabular}

The polycarbonate bars that connect the UAS components were modelled with the elastic-plastic model and it was assumed to be ideal plasticity. The maximum tensile plastic strain was set to be the criterion for element elimination and the parameters listed on tab. 6 were set as found on Olivares et al. [8].

Table 6: Mechanical Properties of Polycarbonate [8]

\begin{tabular}{|c|c|c|c|c|}
\hline$\rho\left[\mathrm{kg} / \mathrm{m}^{3}\right]$ & $\mathrm{E}[\mathrm{GPa}]$ & $v$ & $\sigma \mathrm{y}[\mathrm{MPa}]$ & $\varepsilon_{\max }$ \\
\hline 1180. & 2.35 & 0.3 & 62. & 0.2 \\
\hline
\end{tabular}

\subsection{Computational Model}

The impact analyses of the present study were made through explicit models of Finite Elements using Solution 700 from NASTRAN software. The generation of the mesh elements, the attribution of properties and the inclusion of the applicable parameters to the model were performed using the HYPERMESH software.

\section{FEM Validation}

\subsection{Bird Strike}

In this section, a series of simulations were performed in order to validate the bird model to be used on the design of the WFLE. The formulation adopted to represent the $1.8 \mathrm{~kg}$ bird was the meshless Smooth Particle Hydrodynamics (SPH), which can handle larger deformations compared to other formulations. In SPH technique, the fluid is represented as a set of particles which interaction between them is ruled by interpolation theory and smoothing kernel functions. Hedayati and Ziaei-Rad [15] reported that the hemisphericalended cylinder geometry presented the closest results to experimental data and this is the reason why it was selected as the bird geometry used on the present work.
Bird dimensions and density were calculated using eqs. (4), (5) and (6) proposed by O'Connor [16] after analysing common characteristics of many bird species and different parameters of a bird impact. Bird dimensions are shown in fig. 3 .

Bird Density

$$
\text { Density }=959-63 \cdot \log _{10}(\text { Mass })
$$

Bird Diameter

$$
\text { Diameter }=0,0804 * \text { Mass }^{0,335}
$$

Bird Length

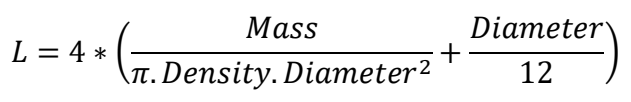
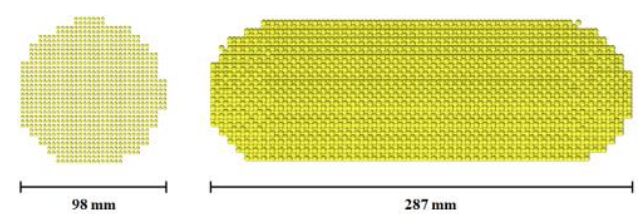

Figure 3: Bird Dimensions

The bird material behaviour is defined by the Equation of State (EOS) that describes the constitutive pressure-volume relationship of a fluid material. Welbeck [17] pointed out that bird material could be consider as a fluid for impacts in high velocities since pressure on bird tissues severely exceeds the tissues tolerable values. Hedayati and Sadighi [18] pointed out that most commonly used EOS for the water bird is a polynomial of degree 3 that corresponds to a hydrodynamic, isotropic, and non-viscous constitutive law, as eq. (7).

$$
\begin{gathered}
P=c_{0}+c_{1} \mu+c_{2} \mu^{2}+c_{3} \mu^{3}+\left(c_{4}+c_{5} \mu+c_{6} \mu^{2}\right) E_{i} \\
c_{1}=\rho_{0} c_{0}{ }^{2} \\
c_{2}=(2 k-1) c_{1} \\
c_{3}=(k-1)(3 k-1) c_{1}
\end{gathered}
$$

Where $E_{i}$ is the internal energy, $\mu$ the change in density during impact, $\rho_{0}$ the density of the medium, $c_{0}$ the speed of sound in the medium and $k$ an experimental constant ( $\mathrm{k}=2$ for water). For negligible initial equilibrium pressures, values of coefficients $c_{4}, c_{5}$ and $c_{6}$ are vanished.

To validate the SPH model used in the present work, it was performed simulations of the bird impacting rigid targets considering three different velocities $(100 \mathrm{~m} / \mathrm{s}, 200 \mathrm{~m} / \mathrm{s}$ and $300 \mathrm{~m} / \mathrm{s})$ and three different impact angles $\left(90^{\circ}, 45^{\circ}\right.$ and $\left.25^{\circ}\right)$. Values obtained for Stagnation Pressure and Impact Force were compared with parameter calculated with eqs. (11) and (12), while Peak Pressure was correlated with experimental results from Barber et al. [19]. Table 7 and fig. 4 present the obtained results. 


$$
\begin{gathered}
P_{s}=\frac{1}{2} \cdot \rho \cdot v_{b}^{2} \\
F_{a v g}=\frac{M \cdot v_{b}^{2} \cdot \sin \theta}{L+D \cdot(\tan \theta)^{-1}}
\end{gathered}
$$

Where $\rho$ is the bird density, $v_{b}$ is the bird initial velocity, $M$ the bird mass, $L$ the bird length, $D$ the bird diameter and $\theta$ the impact angle.

Since tab. 7 shows that values obtained during simulation were higher than the ones found on literature for experimental tests, the bird modelled with SPH methodology and hemispherical-ended geometry was assumed to be conservative.

\begin{tabular}{|c|c|c|c|c|c|c|}
\hline \multirow{2}{*}{$\begin{array}{l}\text { Impact } \\
\text { Angle }\end{array}$} & \multirow{2}{*}{$\begin{array}{c}\text { Impact } \\
\text { Speed } \\
{[\mathrm{m} / \mathrm{s}]}\end{array}$} & \multirow{2}{*}{$\begin{array}{c}\text { Ps } \\
{[\mathrm{MPa}]} \\
\text { Calculated }\end{array}$} & \multicolumn{2}{|c|}{$\begin{array}{c}\mathrm{Ph} \\
{[\mathrm{MPa}]}\end{array}$} & \multicolumn{2}{|c|}{$\begin{array}{c}\text { Impact Force } \\
{[\mathrm{N}]}\end{array}$} \\
\hline & & & Literature & Simulation & Calculated & Simulation \\
\hline \multirow{3}{*}{$25^{\circ}$} & 100 & 4.71 & 20.50 & 53.10 & 15411 & 38673 \\
\hline & 200 & 18.85 & 64.28 & 102.84 & 61644 & 143091 \\
\hline & 300 & 42.42 & 115.82 & 165.22 & 138700 & 302551 \\
\hline \multirow{3}{*}{$45^{\circ}$} & 100 & 4.71 & 42.90 & 121.14 & 33305 & 67282 \\
\hline & 200 & 18.85 & 139.15 & 233.87 & 133220 & 238417 \\
\hline & 300 & 42.42 & 257.06 & 397.69 & 299746 & 532227 \\
\hline \multirow{3}{*}{$90^{\circ}$} & 100 & 4.71 & 79.39 & 130.53 & 63207 & 113758 \\
\hline & 200 & 18.85 & 240.48 & 331.44 & 252827 & 421963 \\
\hline & 300 & 42.42 & 422.71 & 553.09 & 568860 & 867738 \\
\hline
\end{tabular}

Table 7: Bird Impact Simulation Results
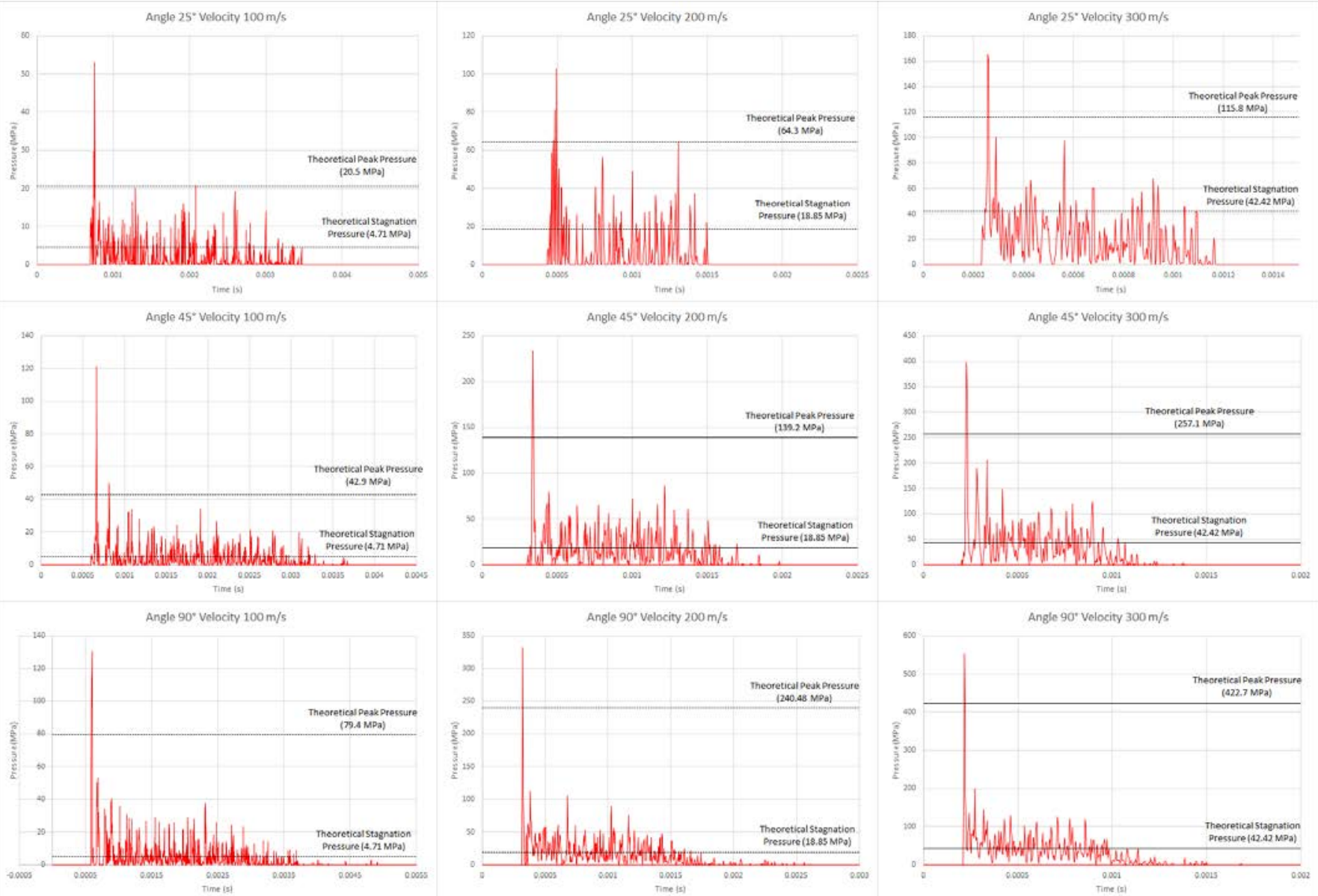

Figure 4: Bird Impact-SPH Model Pressures

\subsection{UAS Impact}

In order to validate the UAS model to be used, impact simulations of its rigid components (battery, motor and camera) were simulated separately. Each component was impacted against Aluminium 2024-T3 flat panels of different thicknesses at velocities of 250 knots and 100 knots. The final results were confronted with ballistic tests data performed on Olivares et al. [8].
Figure 5 shows the simulation performed for each UAS component and tab. 8 presents the correlation between simulation results and experimental data found in the literature. 


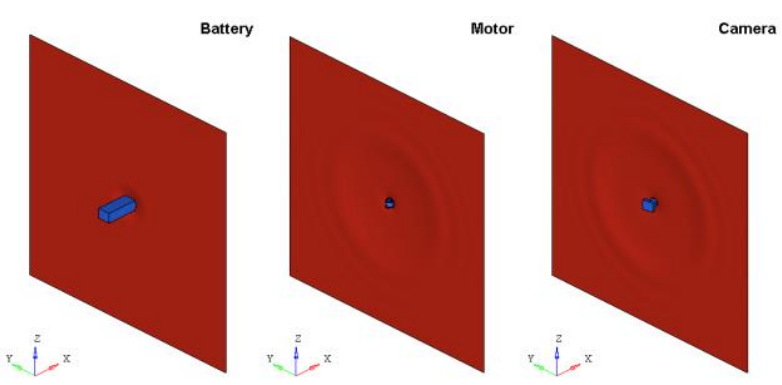

Figure 5: UAS Components Tests Simulation
On the ballistic test, the test setup consisted of two square steel frames bolted together sandwiching about a flat aluminium test panel, while in simulation translation and rotation constrains were attributed to nodes situated in the panel edge. Possibly, differences in the boundary conditions and simplifications adopted on the FE model, like not considering the plastic case that wrap the battery or the different materials on the camera parts, could have induced differences verified on Peak Loads and Maximum Deflection. Nevertheless, it was considered that simulations presented correlation with experimental data and the UAS model was validated.

Table 8: UAS Components Simulation Results

\begin{tabular}{|c|c|c|c|c|c|c|c|c|c|}
\hline \multirow{2}{*}{ Component } & \multirow{2}{*}{$\begin{array}{c}\text { Impact } \\
\text { Velocity }\end{array}$} & Panel Type & \multirow{2}{*}{$\begin{array}{c}\text { Impact } \\
\text { Energy }\end{array}$} & & \multicolumn{2}{c|}{ Panel Penetration } & \multicolumn{2}{|c|}{ Peak Load (N) } & \multicolumn{2}{c|}{ Max Deflection (mm) } \\
\cline { 7 - 11 } & & Literature & Simulation & Literature & Simulation & Literature & Simulation \\
\hline Battery & 250 & $1.6 \mathrm{~mm} \mathrm{Al} \mathrm{2024-T3}$ & 2797.7 & $\mathrm{~N}$ & $\mathrm{~N}$ & 92483 & 106074 & 47.8 & 46.0 \\
\hline Battery & 250 & $6.35 \mathrm{~mm} \mathrm{Al} 2024-\mathrm{T} 3$ & 3034.5 & $\mathrm{~N}$ & $\mathrm{~N}$ & 123892 & 167227 & 19.6 & 22.2 \\
\hline Battery & 100 & $3.18 \mathrm{~mm} \mathrm{Al} \mathrm{2024-T3}$ & 424.6 & $\mathrm{~N}$ & $\mathrm{~N}$ & 48170 & 33603 & 14.5 & 12.7 \\
\hline Motor & 250 & $1.6 \mathrm{~mm} \mathrm{Al} \mathrm{2024-T3}$ & 417.7 & $\mathrm{Y}$ & $\mathrm{Y}$ & 16160 & 21883 & $\mathrm{n} / \mathrm{a}$ & $\mathrm{n} / \mathrm{a}$ \\
\hline Motor & 250 & $6.35 \mathrm{~mm} \mathrm{Al} \mathrm{2024-T3}$ & 473.2 & $\mathrm{~N}$ & $\mathrm{~N}$ & 58703 & 44637 & 7.9 & 9.1 \\
\hline Camera & 250 & $1.6 \mathrm{~mm} \mathrm{Al} \mathrm{2024-T3}$ & 439.0 & $\mathrm{~N}$ & $\mathrm{~N}$ & 31142 & 28768 & 18.5 & 20.6 \\
\hline
\end{tabular}

\section{Aircraft Impacts}

\subsection{Bird Strike}

The bird strike on the WFLE was performed with an impact velocity of $127.0 \mathrm{~m} / \mathrm{s}$ (250 knots) and to be occur at a location between two FLE ribs, considered as a more critical region. Initially, it was set a WFLE skin thickness of $2.0 \mathrm{~mm}$.

In the first attempt, skin presented rupture as shown in fig. 6 . Therefore, another impact was performed increasing the skin thickness to $2.5 \mathrm{~mm}$ in order to evaluate if the aircraft would withstand the dynamic loads from the impact. In this second attempt, a small rupture was verified in the region close to the FLE Rib. A third simulation was performed with a $3.0 \mathrm{~mm}$ thickness on the skin and then all WFLE structure resist without suffer any failure, as shown in fig .7. The maximum effective plastic strain verified on the skin was $20.2 \%$, while the $\mathrm{Al} 2024-\mathrm{T} 3$ rupture strain is $26.0 \%$, approximately, according to calculation performed with data from MMPDS [4].

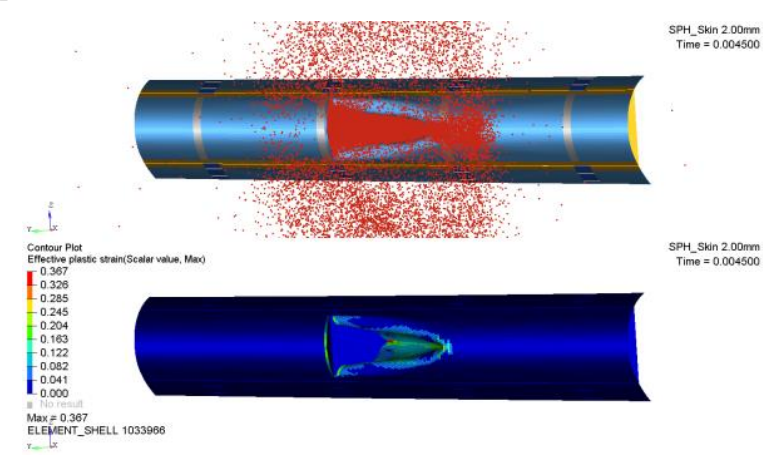

Figure 6: WFLE Bird Impact - thickness $=2.0 \mathrm{~mm}$

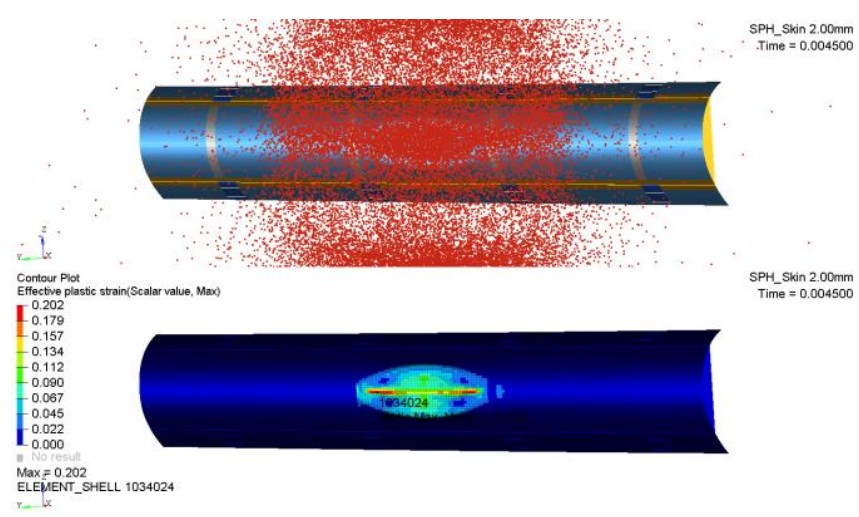

Figure 7: WFLE Bird Impact - thickness $=3.0 \mathrm{~mm}$

\subsection{UAS Impact}

In the same manner as in impact simulations with the bird, the UAS impact simulations considered the impact occurring in a velocity of $127.0 \mathrm{~m} / \mathrm{s}$ (250 knots). This value was calculated from the difference between the maximum speed that the evaluated quadcopter UAS model can reach $(20 \mathrm{~m} / \mathrm{s})$ and maximum speed that paragraph 5-3-8-j.2 (a) of Aeronautical Information Manual [20] establishes for a holding phase on a flight below 6000 feet $(107.0 \mathrm{~m} / \mathrm{s})$.

\subsubsection{UAS Position}

Meng et al. [4] and Olivares et al. [8] performed studies to define the critical location where the UAS impacts a leading edge. Both works reported that when impacting close to the rib, the target structure mostly received damage to the rib and little penetration is verified into the airframe. In contrast, when the impact was centered between ribs, the skin absorbed most of the kinetic energy and the UAS perforated it 
penetrating into the airframe and possibly hitting the spar. Thus, in the simulations performed for the present work, the UAS was positioned to hit the WFLE centered between the two central FLE Ribs.

In order to identify the UAS orientation that could cause the larger damage to the aircraft, five different simulations were performed changing the UAS yaw angle from $0^{\circ}$ to $90^{\circ}$ as shown in fig. 8. The criterion adopted to evaluate which UAS orientation would be the worst was the energy absorbed by the spar and the extension of the damage verified in the WFLE skin. As can be seen in fig. 9, the simulation with the yaw angle of $0.0^{\circ}$ presented the most critical results and for this reason, this position was selected to perform the following UAS impact simulations.

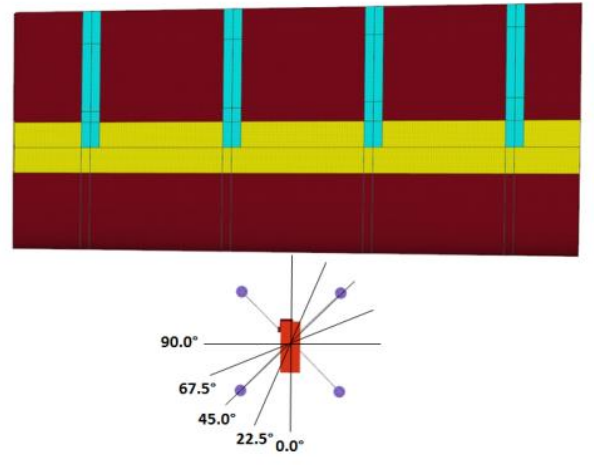

Figure 8: UAS Orientation

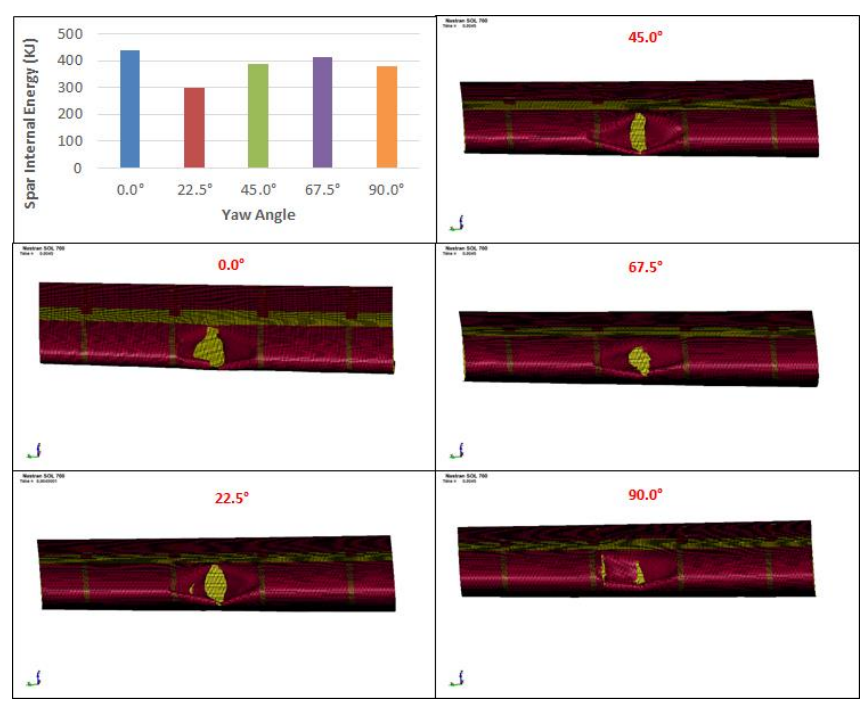

Figure 9: UAS Yaw Angle Simulation Results

\subsubsection{Skin Reinforcement}

As presented in section 4.1, the WFLE with skin thickness of $3.0 \mathrm{~mm}$ was able to withstand the impact with a $1.8 \mathrm{~kg}$ bird. In order to evaluated how critical would be an impact with an UAS, a simulation with the small aerial vehicle was performed considering the WFLE having the same skin thickness.

Simulation results presented in fig. 10 shows that the UAS easily perforated the WFLE skin. Such condition evidences a very critical scenario, once that if the UAS penetrates the airframe, the front spar is exposed to impact with parts of the small aerial vehicle. In case of a front spar rupture, a catastrophic failure would occur. In addition to compromising a primary wing structure, UAS lithium batteries could ignite the fuel present in the wing main box causing a big explosion.

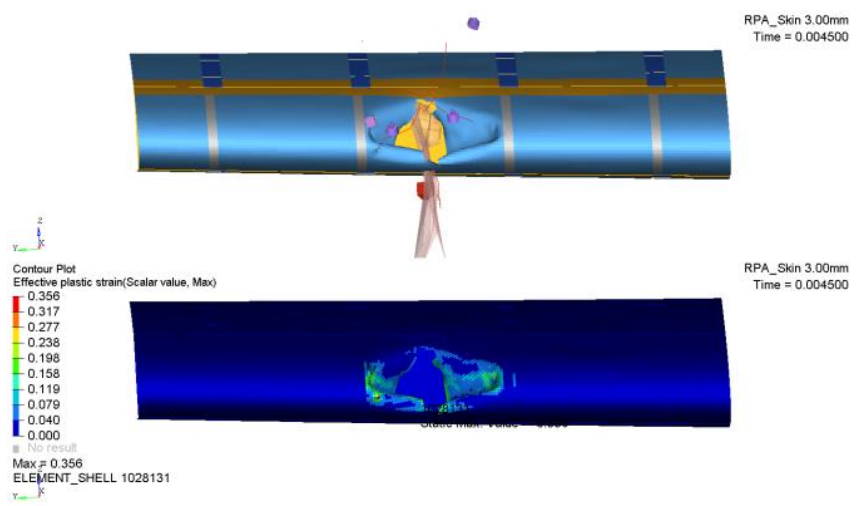

Figure 10: UAS impact in a WFLE with skin thickness of 3.0 $\mathrm{mm}$

In order to evaluate if increasing the skin thickness would be an effective way to make the WFLE resistant to the UAS impact, a simulation was performed considering a skin thickness of $5.0 \mathrm{~mm}$, even though a thick sheet of this order could represent serious difficulties for manufacturing the component. As can be seen in fig. 11, the UAS penetrates the airframe even in a WFLE with a thick Al 2024-T3 skin.

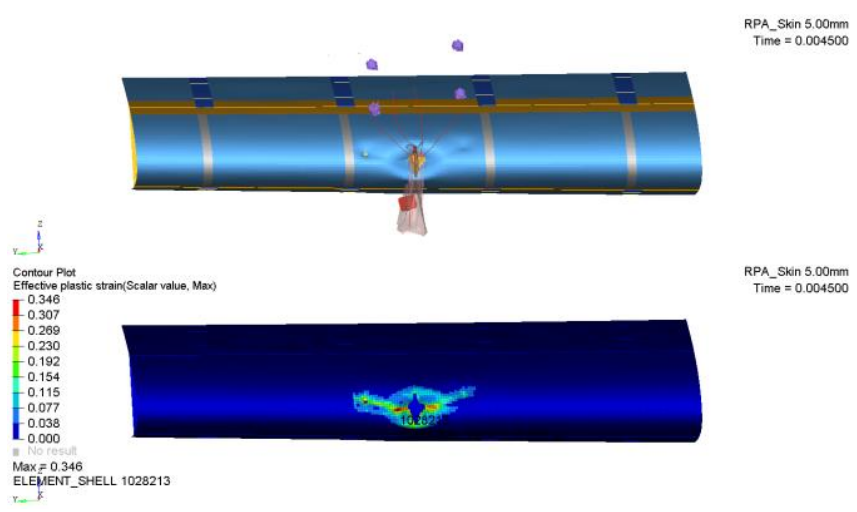

Figure 11: UAS impact in a WFLE with skin thickness of 5.0 $\mathrm{mm}$

\subsubsection{Spar Reinforcement}

Since it was found out that increasing skin thickness would not be an effective way to make the WFLE resistant to UAS impact, an alternative solution would be design the front spar to withstand the impact. To this end, simulations were performed removing the skin from WFLE model and considering the UAS impact to occur directly in the front spar web. Different web thicknesses were investigated for the $\mathrm{Al}$ 7050-T7451 spar and results are shown in fig. 12 to fig. 14. From fig. 14, it can be noticed that no rupture occur on spar web with a thickness of $12.0 \mathrm{~mm}$, although the effective plastic strain detected was very close to the material rupture strain. 


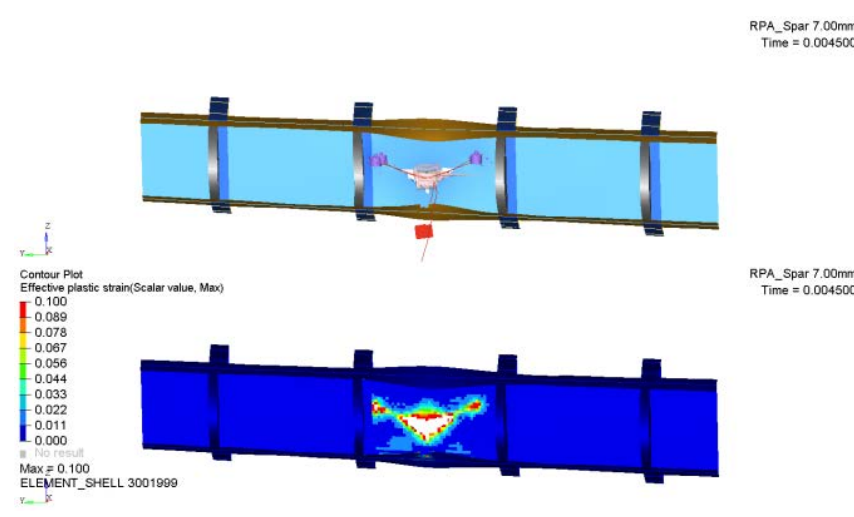

Figure 12: UAS Impact in Spar with Web Thickness of 7.0 $m m$

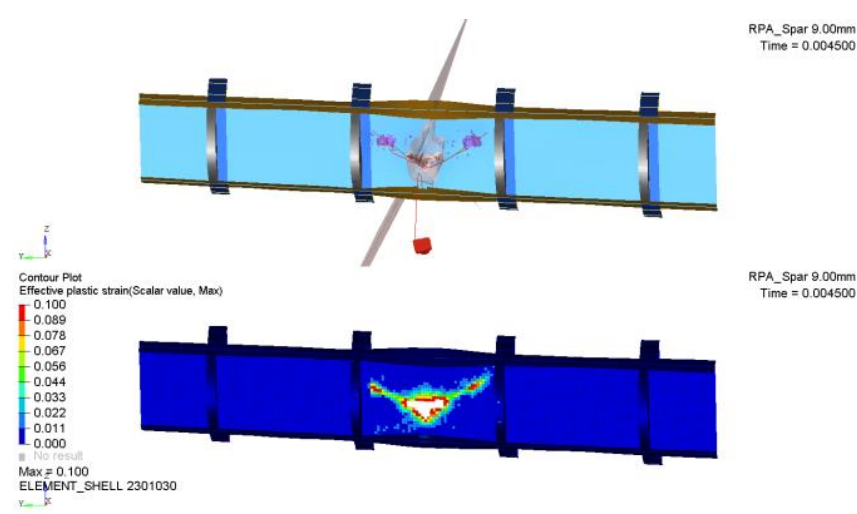

Figure 13: UAS Impact in Spar with Web Thickness of 9.0 $m m$

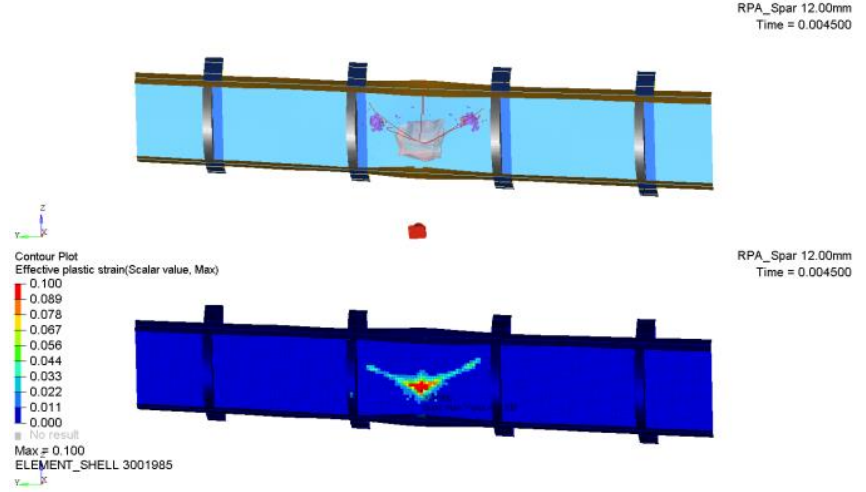

RPA_Spar $12.00 \mathrm{~mm}$
Time $=0.004500$

Figure 14: UAS Impact in Spar with Web Thickness of 12.0 $\mathrm{mm}$

Other reinforcement in the spar were also evaluated adding stiffeners on its back region in order to reduce the web deformation. The stiffeners dimensions were $26.5 \mathrm{~mm}$ x 4.0 $\mathrm{mm}$ and the web thickness considered was $7.0 \mathrm{~mm}$. On fig. 15 it is shown that a small rupture occurred on region where stiffener was not added.

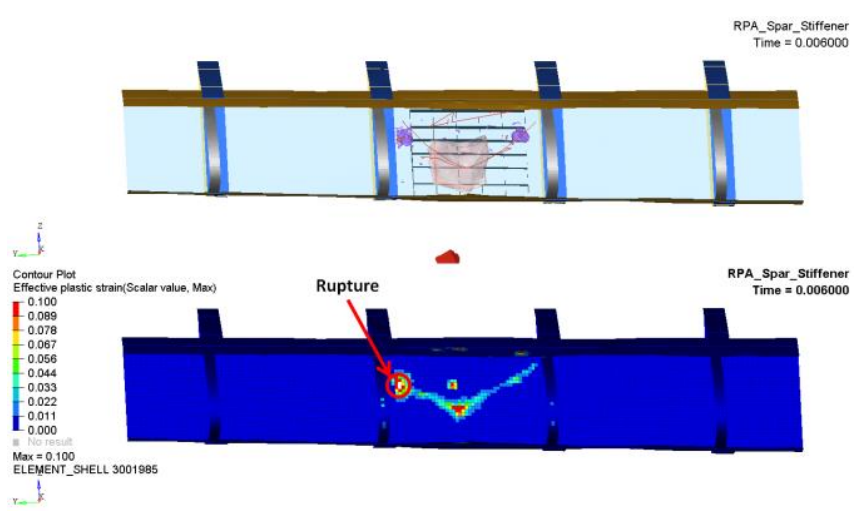

Figure 15: UAS Impact in Spar with Spines (26.5 $\times 4.0 \mathrm{~mm})$

\section{Discussions}

\subsection{Bird Strike X UAS Impact}

During the present work it was verified that the mid-air collision with an UAS is much more severe for an aircraft than an impact with a bird. Even though the energy considered for both impacts (same mass and same velocities were considered on simulations), while the bird impact did not cause the rupture of a WFLE skin with a thickness of 3.0 $\mathrm{mm}$, the UAS easily perforated the skin and caused a damage of $125.8 \mathrm{~mm}$, as shown on fig. 16 .

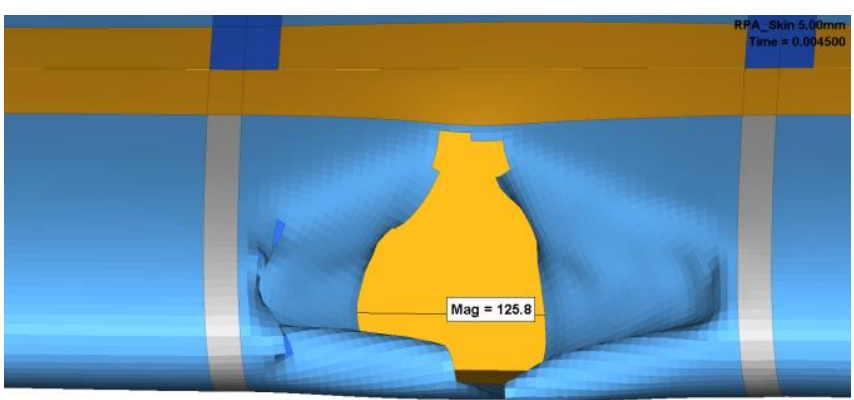

Figure 16: Damage cause by the UAS Collision

The first reason that could explain this difference refers to the material behaviour during impact. The bird was modelled with a fluid material that splashes when hit the aircraft, increasing the contact area and consequently reducing the pressure applied on the WFLE skin. Meanwhile, the UAS was represented with solid elements that apply concentrated loads on the WFLE, inducing higher local deformation and consequently causing the material failure.

The other reason that could explain the larger damage caused by the UAS impact is associated to its stiffness. While the bird was treated as a homogenous body during simulations validated with test results, the UAS was modelled with components made of different materials, all of them much harder and resistant than the one considered for the bird. The rigid structures battery, motors and camera induce higher loads in the WFLE and local stress regions during the impact. As can be seen on fig. 17, the contact force amplitude for the UAS impact is higher than the one for bird strike. 


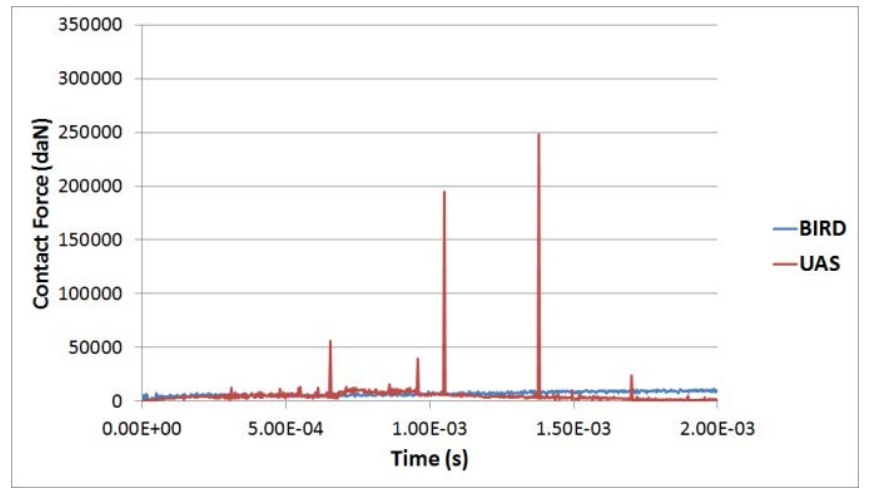

Figure 17: Contact Forces for Bird and UAS Impact

\subsection{Skin and Spar Reinforcements}

The evaluation of reinforcements in the WFLE in order to make it resistant to UAS collision demonstrated that increase in spar thickness would be more effective than in skin thickness. In general, the spar web thickness is much thicker than WFLE skin due to necessity of spar withstand limit loads that could occur in the aircraft during a flight in case of a maneuver or a system failure. If the skin thickness were increased until it not rupture during UAS collision, the amount of weight added to the WFLE could be so large that would reduce drastically the performance of a commercial aircraft. In addition, other problems associated with thicker skins would also have to be evaluated, such as difficulty on forming thick aluminum sheets and excessive energy consumption for heating the leading edge in order to prevent ice formation.

For reinforcements in the spar, two configurations were evaluated: 1) Thicker web thickness; and 2) Additional stiffeners on its back region. The stiffeners would not be so effective since the UAS impact loads occur in small concentrated regions in a way that to the stiffeners work properly, they should be positioned exactly where the higher loads occur. Considering the impossibility to determining the exact point where the impact will occur in the wing, a large number of stiffeners would have to be added.

On tab. 9 it is presented a weight comparison between the WFLE dimensioned with skin thickness of $3.0 \mathrm{~mm}$ able to withstand the impact with the bird and the WFLE's that could resist to the UAS collision after adding reinforcements on its spar increasing the spar web thickness and adding stiffeners on its back region. Although the stiffeners are not very effective, the WFLE reinforced with them had less added mass than the one reinforced only with spar web thickness. It is important to notice that values on tab. 9 refers only to the part of WFLE considered on simulations, which have a length of $1435 \mathrm{~mm}$. In large commercial aircrafts, the WFLE could reach almost $35.0 \mathrm{~m}$ in each half wing.
Table 9: WFLE Weight Comparison

\begin{tabular}{|c|c|c|}
\hline & $\begin{array}{c}\text { Weight } \\
(\mathrm{kg})\end{array}$ & $\begin{array}{c}\text { Added } \\
\text { Mass (kg) }\end{array}$ \\
\hline $\begin{array}{c}\text { WFLE dimensioned with Bird } \\
\text { Strike }\end{array}$ & 31.6 & - \\
\hline $\begin{array}{c}\text { WFLE dimensioned with UAS } \\
\text { impact (spar web thickness) }\end{array}$ & 35.8 & +4.2 \\
\hline $\begin{array}{c}\text { WFLE dimensioned with UAS } \\
\text { impact (spar with stiffeners) }\end{array}$ & 35.6 & +3.6 \\
\hline
\end{tabular}

In future works, it could be evaluated the use of additional structures that split the UAS before it reaches the front spar, in the same way that it is already done with birds in some aircrafts. The applicability of alternative materials, such as honeycombs, could also be studied as means to make the WFLE withstand the impact with harder components. Other aircrafts regions as the windshield, engines and horizontal and vertical empennages also have to be analyzed with the UAS impact since all of them are exposed to this kind of occurrence. Finally, more experimental tests with UAS impact in a real aircraft structure have to be done in order to increase the validity of computational models and numerical simulations.

\section{Conclusion}

In the present work, it was analysed numerically a bird and a UAS impact against aircraft Wing Fixed Leading Edge. The bird strike simulations were developed and validated with experimental data obtained in literature, while the UAS collision was validated with results from ballistic tests found in the literature performed with different parts of the UAS. Both impact scenarios in the WFLE were compared and reinforcements were evaluated. The following conclusions $f$ can be highlighted:

1) The impact behaviour simulated by the FE model developed in this work was in acceptable agreement with test data;

2) The commercial airliner must be reinforced so it could complete the flight safely when a UAS airborne collision happens at its cruising speed. The damage to the WFLE spar and fire risk of the lithium-ion battery must be take into account;

3) UAS impact would cause more damages in a WFLE than bird strike considering the same mass. The UAS penetrated the skin and could cause damages on primary structures of the aircraft, like the front spar. Relevant airworthiness standards should be developed to ensure the safety operation of commercial flights;

4) Reinforcements on the WFLE spar web proofed to be more efficient than reinforcements in the skin. For future works, additional structures could be evaluated in the WFLE to split the UAS before it reaches the spar.

\section{Acknowledges}

The authors would like to thank the Fundação de Desenvolvimento da Pesquisa (FUNDEP) for the financial support to participate in the Aerospace Technology Congress 
2019 and the Fundação de Amparo à Pesquisa do Estado de Minas Gerais (FAPEMIG) and Conselho Nacional de Desenvolvimento Científico e Tecnológico (CNPq) for their research supports.

\section{References}

[1] JENKINS D.; VASIGH B. The economic impact of unmanned aircraft systems integration in the United States, Association for Unmanned Vehicle Systems International (AUVSI). P. 1-40, 2013

[2] SHARMA, R. S. Investigation into Unmanned Aircraft System Incidents in the National Airspace System. International Journal of Aviation, Aeronautics, and Aerospace, Article 2, Volume 3, Issue 4, 2016.

[3] WILD, G.; MURRAY, J.; BAXTER, G. Exploring Civil Drone Accidents and Incidents to Help Prevent Potential Air Disasters. Aerospace 2016, 3, 22.

[4] MENG, X.; SUN, Y.; YU, J.; TANG, Z.; LIU, J.; SUO, T.; LI, Y. Dynamic response of the horizontal stabilizer during UAS airborne collision. International Journal of Impact Engineering, 126, p.50-61, 2019.

[5] OLIVARES, G.; LACY, T.; GOMEZ, L.; ESPINOSA DE LOS MONTEROS, J.; BALDRIDGE, R. J.; ZINZUWADIA, C.; ALDAG, T.; KOTA, K. R.; RICKS, T.; JAYAKODY, N. UAS Airborne Collision Severity Evaluation - Executive Summary - Structural Evaluation. Federal Aviation Administration, Report $D O T / F A A / A R-X X / X X, 2017 \mathrm{a}$.

[6] BRITISH MILITARY AVIATION AUTHORITY, Small Remotely Piloted Aircraft Systems (drones) Mid-air Colision Study. Report-16, 2016.

[7] GOKHALE, N. S.; DESHPANDE, S. S.; BEDEKAR S. V.; THITE, A. N. Practical Finite Element Analysis. Finite to Infinite, 2008.

[8] OLIVARES, G.; GOMEZ, L.; ZINZUWADIA, C.; ESPINOSA DE LOS MONTEROS, J.; BALDRIDGE, R. J.; ALDAG, T. UAS Airborne Collision Severity Evaluation - Volume II - Quadcopter. Federal Aviation Administration, Report DOT/FAA/AR$X X / X X, 20 \mathrm{~mm} 17 \mathrm{~b}$.

[9] CAIRNS, D. S.; JOHNSON, G.; EDENS, M.; ARNOLD, F. Volume I - UAS Airbone Collision Severity Evaluation - Projectile and Target Definition. Federal Aviation Administration, Report DOT/FAA/AR-XXX/XX, 2016.

[10] JOHNSON, G. R. A constitutive model and data for metals subjected to large strains, high strain rates and high temperatures. Proceedings of the $7 \mathrm{th}$ international symposium on Ballistics, 1983.
[11] KAY, G. Failure Modeling of Titanium 6Al-4V and Aluminum 2024-T3 With the Johnson-Cook Material Model", Report DOT/FAA/AR-03/57, Federal Aviation Administration, 2003.

[12] MMPDS-09, Metallic Material Properties Development and Standardization (MMPDS), Chapter 9, Ed. 7, Battelle Memorial Institute, 2014.

[13] "520.0 (520.0-T4, formerly 220.0, LM10, G10A, A05200) Cast Aluminum", URL:

https://www.makeitfrom.com/materialproperties/520.0-520.0-T4-formerly-220.0-LM10G10A-A05200-Cast-Aluminum

[14] SAHRAEI, E., MEIER J., WIERZBICKI, T. Characterizing and modeling mechanical properties and onset of short circuit for three types of lithium-ion pouch cells. Journal of Power Sources, Volume 247, p. 503-516, 2014.

[15] HEDAYATI, R.; ZIAEI-RAD, S. Effect of bird geometry and orientation on bird-target impact analysis using SPH method. International Journal of Crashworthiness, Volume 17, p. 445-459, 2013.

[16] O'CONNOR, J. The Hazard Posed to Aircraft by Birds - Attachment B. Australian Transport Safety Bureau, 2002.

[17] WILBECK, J. S. Impact behavior of low strength projectiles. PhD dissertation, Texas AM University, 1978.

[18] HEDAYATI, R.; SADIGHI, M. Bird Strike - An Experimental, Theoretical, and Numerical Inverstigation. Woodhead Publishing in Mechanical Engineering, 2016.

[19] BARBER, J. P.; TAYLOR, H.R.; WILBECK, J. S. Bird Impact Forces and Pressures on Rigid and Compliant Targets. Wright-Patterson Dynamic Laboratory - AFFDL-TR-77-60. May, 1978.

[20] AERONAUTICAL INFORMATION MANUAL. Official Guideline to Basic Flight Information and ATC Procedures. Federal Aviation Administration, 2017. 